\title{
GENETIC MARKERS OF COVID-19 SUSCEPTIBILITY
}

\author{
GEOFFREY KEITH CHAMBERS ${ }^{1}$ AND HISHAM ATAN EDINUR ${ }^{2,3,4 *}$
}

\begin{abstract}
${ }^{1}$ School of Biological Sciences, Victoria University of Wellington, PO Box 600, Wellington, New Zealand. ${ }^{2}$ School of Health Sciences, Universiti Sains Malaysia,Health Campus, 16150 Kubang Kerian, Kelantan, Malaysia. ${ }^{3}$ Intitute of Tropical Biodiversity and Sustainable Development, Universiti Malaysia Terengganu, 21030, Kuala Nerus, Terengganu, Malaysia. ${ }^{4}$ Environmental Futures Research Institute, Griffith University, Nashan, Queensland, 4111, Australia.
\end{abstract}

*Corresponding author: edinur@usm.my

Submitted final draft: 29 May $2020 \quad$ Accepted: 31 May 2020

http://doi.org/10.46754/jssm.2021.08.001

\begin{abstract}
The COVID-19 pandemic is a serious threat to human health. Governments worldwide have put urgent measures in place to deal with this threat. Considerable experiences have been gained during this process, and they have gone a long way towards developing effective management strategies to control the spread of the coronavirus. Nonetheless, it is important that these efforts should be underpinned by investigations based on medical science. In this letter, we advocate widespread screening of human leukocyte antigen (HLA) markers and other immunologically significant genetic loci. We believe that these data will allow medical professionals to establish schedules of relative risk on patients following exposure to COVID-19. We suggest that this survey be facilitated by the establishment of a "biobank" containing samples from symptomatic and non-symptomatic individuals who test positive for COVID-19.
\end{abstract}

Keywords: COVID-19, management strategies, HLA, KIR, cytokines.

Abbreviations: Severe acute respiratory syndrome coronavirus 2 (SARS-CoV-2), human leukocyte antigen (HLA), killer cell immunoglobin-like receptors (KIR).

\section{Introduction}

The global coronavirus disease (COVID-19) pandemic caused by severe acute respiratory syndrome coronavirus-2 (SARS-CoV-2) represents the most serious challenge to public health since the 1918 Influenza Pandemic (Mat et al., 2020; Edinur \& Abdullah, 2020). Besides disrupting life as we used to know, it has severely interrupted world trade, causing great damage to domestic economies. Considerable resources have been devoted to control the spread of this virus and treating patients. Short-term relief via pharmaceutical agents and long-term prevention via vaccination are both important goals in knowledge-based medicine. Sadly, both still seem to be distant prospects. However, it remains important to increase efforts to understand the basic biology of SARS-CoV-2, so that the strategies noted may become a primary importance to understand the response of the human immune system towards COVID-19. A first step towards this objective is to screen for genetic markers, including the human leukocyte antigen (HLA), killer-cell immunoglobin-like receptors (KIR) and cytokine loci. We further suggest that this screening initiative to be facilitated by the establishment of a "biobank" to collect DNA samples from infected individuals.

\section{Research Strategy}

We wish to endorse the call by Edinur and Abdullah (2020) for rapid publication of articles on COVID-19 research. Indeed, it is self-evident that during this public health emergency, it is vital that such research be funded, carried out and reported as quickly as possible. Work on strategies likely to make a real difference to present outcomes should take priority. They include methods for the detection of infected persons, treatment methods like vaccine development and patient management, and effective public health practices and engagement, among others.

For the programme to be most effective, it is equally important that it should be underpinned by basic research in coronavirus biology and human genetics. We point to the value of gaining 
knowledge about immune system markers across various ethnic groups that make up the local population. These markers are complex and hypervariable, with a wide range of rapid defensive responses to various infectious agents (Gozalez-Galarza et al., 2015; Robinson et al., 2013), and they are known to differ greatly between ethnicities. This is also true in Malaysia and New Zealand, as many of our previous studies have reported (Edinur et al., 2013; 2018; Nemat-Gorgani et al., 2014; Norhalifah et al., 2016; Norhalifah et al., 2018).

We recommend a genetic screening of immune markers because we believe that this information will allow medical professionals to answer some important questions, and thereby provide evidence-based advice to those on the frontlines. One of the questions include: "Do the relative COVID-19 disease incidences between ethnic groups reflect immune response or social conditions?" Knowing more about HLA/ $\mathrm{KIR} /$ cytokine profiles in relation to disease progression should allow the establishment of relative risk schedules and provide pointers to best practice triage strategies. These data may also help to indicate if the most severe cases result from an immune/inflammatory response to infection via a "cytokine storm" syndrome (Mehta et al., 2020). It is also helpful to know which patient will or will not likely develop antibody profiles post-infection in relation to their potential to become re-infected. This type of information will also be valuable in determining the extent of a community spread, especially by non-symptomatic individuals.

It is very encouraging to see that scientists elsewhere are independently thinking along the same lines. For instance, the 18th International HLA \& Immunogenetics Workshop (IHIWS) has established a website called HLA COVID-19 (http://hlacovid19.org) to act as a clearing house for new information. This site contains one new report on theoretical antigen-binding studies (Nguyen et al., 2020) and a compilation of clinical survey data (Sanchez-Mazas, 2020), listing putative susceptibility and resistance markers. This integrated worldwide effort is very valuable, but Malaysia still needs to mount its own screening effort. This is because most of the domestic population is of Austronesian descent (Edinur et al., 2018), and such people are rarely represented in overseas studies. It is well known that Austronesian people have a genepool shaped by ancestry, population level processes (including admixture) and natural selection. None of the markers identified so far appear to be present in Austronesians (Edinur et al., 2013, 2018).

An added imperitive is the recent news reports in Los Angeles in the United States, which suggest that the natives of Hawaii and other Pacific Islands (who are also of Austronesian descent) are particularly (two- to three-fold) susceptible to COVID-19 infection (Radio New Zealand, 27-APR-20). It is also important that data everywhere be collected at a large scale because individuals respond differently to COVID-19 infection. Indeed, there is considerable variation in their clinical presentation. The majority are asymptomatic or experience only very mild symptoms, while a small percentage may present with severe disease that leads to death. Thus, it is of great importance to understand why only some patients become critically ill, and to search for markers of this predisposition.

\section{Conclusion}

In conclusion, we feel that work on the programme that we have proposed is of such great importance and it should begin at once, even if resources are not immediately available to carry out all analyses. Thus, an essential "insurance step" will be to establish a biobank of DNA samples from as many COVID-19 positive individuals as possible, together with their full three-generation pedigrees. These latter ancestry-defined ethnicity data are required in the interest of social equity because some groups may be more susceptible than others. The biobank sample collection should be expanded to include individuals who are non-symptomatic but turn out to be antibody positive. In the long term, it will also have the added value of being able to serve as a reference 
standard for inter-laboratory validation. Overall, it will represent a significant resource in making informed decisions to understand and, thereby, limit the present COVID-19 crisis.

\section{Acknowledgements}

Geoffrey Keith Chambers acknowledges the alumnus scholar support given by Victoria University, and the authors like to acknowledge the financial support provided by Ministry of Higher Education (Fundamental Research Grant Scheme: FRGS/1/2020/STG03/USM/03/5). Both authors also like to thank the reviewers who gave their constructive advice in this letter.

\section{References}

Edinur, H. A., Rasudin, N. S., Ghafar, N. A., \& Chambers, G. K. (2018). The Austronesian Diaspora from an HLA Perspective. In Berhardt L.V. (Ed.), Advances in Medicine and Biology (pp.99-137). Nova Science Publishers.

Edinur, H., Dunn, P. P., Hammond, L., Selwyn, C., Brescia, P., Askar, M., Reville P., Velickovic Z. M., Lea R. A., \& Chambers, G. K. (2013). HLA and MICA polymorphism in Polynesians and New Zealand Maori: Implications for ancestry and health. Human Immunology, 74(9), 1119-112.

Edinur, H. A., \& Abdullah, M. T. (2020). The Journal of Sustainability Science and Management responds to coronavirus SARS-Cov-2 emergence. Journal of Sustainability Science and Management, 15(3), 1-2.

González-Galarza, F. F., Takeshita, L. Y., Santos, E. J., Kempson, F., Maia, M. H. T., da Silva, A. L. Teles e Silva A. L., Ghattaoraya, G. S., Alfirevic, A., Jones, A. R., \& Middleton D. (2015). Allele frequency net 2015 update: New features for HLA epitopes, KIR and disease and HLA adverse drug reaction associations. Nucleic Acids Research, 43(D1), D784-D788.

Mat, N. F. C., Edinur, H. A., Razab, M. K. A. A., \& Safuan, S. (2020). A single mass gathering resulted in massive transmission of COVID-19 infections in Malaysia with further international spread. Journal of Travel Medicine, 27(3), 1-4.

Mehta, P., McAuley, D. F., Brown, M., Sanchez, E., Tattersall, R. S., \& Manson, J. J. (2020). COVID-19: Consider cytokine storm syndromes and immunosuppression. The Lancet, 395(10229), 1033-1034.

Nemat-Gorgani, N., Edinur, H. A., Hollenbach, J. A., Traherne, J. A., Dunn, P. P., Chambers, G. K., Parham P., \& Norman, P. J. (2014). KIR diversity in Māori and Polynesians: Populations in which HLA-B is not a significant KIR ligand. Immunogenetics, 66(11), 597-611.

Norhalifah, H. K., Mat, N. F. C., \& Edinur, H. A. (2018). Cytokine Gene Polymorphisms in cancer and inflammatory disorders. Current Immunology Reviews, 14(2), 81-93.

Norhalifah, H. K., Syafawati, W. U., Che Mat, N. F., Chambers, G. K., \& Edinur, H. A. (2016). Distribution of cytokine gene polymorphisms in six Orang Asli subgroups in Peninsular Malaysia. Human Immunology, 77(4), 338-339.

Nguyen, A., David, J. K., Maden, S. K., Mary, A., Wood, M. A., Weeder, B. R., Nellore, A., \& Thompson, R. F. (2020). Human leukocyte antigen susceptibility map for SARS-CoV-2. Virology, in press.

Radio New Zealand. (2020). High COVID-19 rates for Pacific Islanders in the US. www.rnz.co.nz/international/pacificnews/415195.

Robinson, J., Halliwell, J. A., Hayhurst, J. D., Flicek, P., Parham, P., \& Marsh, S. G. (2015). The IPD and IMGT/HLA database: Allele variant databases. Nucleic Acids Research, 43(D1), D423-D431.

Sanchez-Mazas, A. (2020). HLA studies in the context of coronavirus outbreaks. Swiss Medical Weekly, 150(15), w20248. 